\title{
Heats of Combustion and Solution of Liquid Styrene and Solid Polystyrene, and the Heat of Polymerization of Styrene
}

\author{
By Donald E. Roberts, William W. Walton, and Ralph S. Jessup
}

\begin{abstract}
Bomb-calorimetric measurements have yielded for the heats of combustion $\left(-\Delta H_{c}{ }^{\circ}\right)$ at $25^{\circ} \mathrm{C}$ of liquid styrene and solid polystyrene to form gaseous carbon dioxide and liquid water the values $4394.88 \pm 0.67 \mathrm{int} . \mathrm{kj} / \mathrm{mole}(1050.58 \pm 0.14 \mathrm{kcal} / \mathrm{mole})$, and $4325.09 \pm 0.42 \mathrm{int}$. $\mathrm{kj} / \mathrm{C}_{8} \mathrm{H}_{8}$-unit ( $1033.89 \pm 0.10 \mathrm{kcal} / \mathrm{C}_{8} \mathrm{H}_{8}$-unit), respectively, and for the heat of polymerization of liquid styrene to solid polystyrene at $25^{\circ} \mathrm{C}$ the value $69.79 \pm 0.66 \mathrm{int}$. $\mathrm{kj} / \mathrm{mole}(16.68 \pm 0.16$ $\mathrm{kcal} / \mathrm{mole})$. The results obtained on two samples of polystyrene of different molecular weight were in agreement within the precision of the measurements.

Measurements of the heat of solution of solid polystyrene in liquid monomeric styrene gave the value $3.59 \pm 0.21 \mathrm{int}$. $\mathrm{kj}(0.86 \pm 0.05 \mathrm{kcal})$ evolved per $\mathrm{C}_{8} \mathrm{H}_{8}$-unit of polystyrene at $25^{\circ} \mathrm{C}$. Addition of this to the value for the heat of polymerization of liquid styrene to solid polystyrene gives the value $73.38 \pm 0.69 \mathrm{int}$. $\mathrm{kj}(17.54 \pm 0.16 \mathrm{kcal})$ per mole of styrene for the heat of polymerization of liquid styrene at $25^{\circ} \mathrm{C}$, when the final product is a solution of polystyrene in styrene containing 6.9 percent by weight of polystyrene.
\end{abstract}

\section{Introduction}

The heat of polymerization of styrene can be obtained directly by measuring the heat evolved when the polymerization reaction is allowed to take place in a calorimeter, or it can be obtained indirectly as the difference between the heats of combustion of liquid monomer and solid polymer. In the direct measurement, the polymerization is not complete, as a rule, so that the heat evolved is that corresponding to a polymerization reaction in which the final product is a solution of polymer in monomer. The indirect determination, on the other hand, yields the heat of polymerization of the liquid monomer to solid polymer. In order to compare values of heat of polymerization obtained by the two methods it is necessary to have a value for the heat of solution of polymer in monomer.

\footnotetext{
1 Presented before the High Polymer Forum at the 110th meeting of the American Chemical Society, Chicago, Sept. 11, 1946. This paper also will appear in the J. Polymer Sci. 2, No. 3 (1947).
}

Although the indirect determination has the disadvantage that the heat of polymerization is obtained as the small difference between two large quantities, the precision of bomb-calorimetric measurements is such that the accuracy of the indirect determination is comparable with that of direct determinations which have been reported $[1,2] .^{2}$ The indirect method has the advantage that the effect of the molecular weight of the product on the heat of polymerization can be investigated by using polymer fractions of widely different molecular weights.

The purpose of this paper is to present results of bomb-calorimetric measurements on styrene and on two samples of polystyrene having different average molecular weights, and a value of heat of polymerization derived therefrom. Data obtained in measurements of the integral heat of solution of polystyrene in liquid styrene, which can be

\footnotetext{
${ }^{2}$ Figures in brackets indicate the literature references at the end of this
} paper. 
used to compare the results of the measurements reported here with values obtained by direct measurements of heat of polymerization made at this Bureau [1] are also given. In themselves, calorimetric determinations of partial molar heats of solution are of importance in connection with studies of thermodynamic properties of polymer solutions, and as the dependence of heat of solution upon concentration is not yet known, further work is contemplated.

\section{Methods and Apparatus}

In this work, measurements of heats of combustion of liquid monomer and solid polymer were made with the same bomb calorimetric system, and the difference in the results was taken as the heat of polymerization of liquid monomer to solid polymer. In calculating the results of the measurements of heat of combustion, the amount of the combustion reaction in each experiment was derived from the mass of carbon dioxide formed, using the value 44.010 for the molecular weight of carbon dioxide.

The calorimetric system was calibrated with Standard Sample 39f of benzoic acid, using the value reported previously [3] for the heat of combustion of this sample under the conditions of the bomb process.

The observed heat of combustion in each experiment was corrected for heat of stirring and heat transfer between calorimeter and surroundings, for energy used to ignite the charge, and for energy produced by formation of nitric acid in the bomb. In the experiments with polystyrene a small amount $(0.14$ to $0.36 \mathrm{mg})$ of unburned carbon was left in the crucible. Correction for this was applied both to the observed mass of carbon dioxide formed and to the observed heat of combustion using 33 int. $\mathrm{kj} / \mathrm{g}$ as the heat of combustion of carbon.

The observed value of heat of combustion in each experiment was reduced, in accordance with the procedure described by Washburn [4], to the value of $-\Delta U_{c}^{\circ}\left(25^{\circ} \mathrm{C}\right)$, the decrease in intrinsic energy accompanying the combustion reaction

$$
\mathrm{C}_{8} \mathrm{H}_{8}+10 \mathrm{O}_{2}(\mathrm{~g}) \rightarrow 8 \mathrm{CO}_{2}(\mathrm{~g})+4 \mathrm{H}_{2} \mathrm{O} \text { (liq) }
$$

with each of the reactants and products in its thermodynamic standard state. The standard state for $\mathrm{C}_{8} \mathrm{H}_{8}$ in this equation is that of the liquid monomer or solid polymer at $25^{\circ} \mathrm{C}$ and a pressure of 1 atmosphere.

The heat evolved at $25^{\circ} \mathrm{C}$ in the polymerization reaction per mole of monomer $-\Delta U_{P}{ }^{\circ}\left(=-\Delta H_{P}{ }^{\circ}\right)$ was then calculated by means of the relation $-\Delta U_{P}{ }^{\circ}=\left(-\Delta U_{c}{ }^{\circ}\right)_{m}-\left(-\Delta U_{c}^{\circ}\right)_{p}$, where the subscripts $m$ and $p$ refer to liquid monomer and solid polymer, respectively.

The samples of polystyrene, which were fine powders, were compressed into pellets and then weighed in the platinum crucible in which they were to be burned. The samples of liquid styrene were enclosed in thin-walled glass bulbs $[5,6]$ which were flattened on opposite sides and filled completely with the liquid. The method described in the references cited for filling such bulbs consisted in immersing the end of the stem in the liquid, and then alternately heating the bulb to expel air, and allowing it to cool and draw in liquid. As it was thought undesirable to heat the styrene, a different method of filling the bulbs was used. This method consisted in immersing the end of the stem in the liquid, and then alternately applying pressure gently with the fingers to the flat sides of the bulb to expel air, and releasing the pressure. The weight of glass in each bulb after removing the stems was about $0.05 \mathrm{~g}$.

The apparatus and procedure followed in the bomb-calorimetric measurements have been described previously $[7,8,9]$. The bomb used is made of illium and is similar in design to that described by Prosen and Rossini [10]. The bomb had a capacity of $380 \mathrm{ml}$. One milliliter of water was placed in the bomb before each combustion experiment. The carbon dioxide formed in combustion was absorbed in Ascarite and weighed, following the procedure described by Rossini [11]. The absorption train used was similar to that described in reference [10], but no provision was made for oxidizing products of incomplete combustion and absorbing the resulting carbon dioxide. However, frequent tests for carbon monoxide in the gaseous products of combustion were made, using an NBS colorimetric method [12], but no carbon monoxide was ever found.

The heat of solution of polystyrene in liquid styrene was determined by observing the temperature rise of the calorimeter produced by the solution of about $1 \mathrm{~g}$ of polystyrene in $15.0 \mathrm{ml}$ of styrene. 
The calorimetric apparatus used in the measurements of the heat of solution was the same as that used in the combustion experiments, except that the calorimeter cover was omitted, and a straight glass tube about $300 \mathrm{~mm}$ in length by $11.5 \mathrm{~mm}$ inside diameter was used to contain the sample of liquid styrene. This tube was immersed to a depth of $225 \mathrm{~mm}$ in the water of the calorimeter and extended about $40 \mathrm{~mm}$ above the jacket. The finely powdered sample of polystyrene was contained in a cylinder $10 \mathrm{~mm}$ in diamter and 110 mm long made of 200-mesh copper gauze, which was placed in the glass tube above the surface of the liquid styrene, and was suspended by a thinwalled copper-nickel tube. The temperatures of the calorimeter and jacket were both brought near to $30^{\circ} \mathrm{C}$, with the temperature of the jacket slightly higher than that of the calorimeter, so that there was a small positive rate of change of calorimeter temperature due to thermal leakage. After a wait of several minutes for the attainment of a steady positive rate, a series of observations of calorimeter temperature and corresponding time was made over a period of 10 minutes. The copper-gauze cylinder containing the sample of polystyrene was then lowered into the styrene and moved up and down by hand once a second to stir the liquid. The temperature of the calorimeter rose rapidly at first, but the rate of rise decreased with time and attained a small constant value after about 10 minutes, indicating that solution of the polystyrene was complete. Stirring of the solution was continued for 10 more minutes, and readings of time and temperature were continued for 10 minutes after the stirring was stopped. The rate of change of calorimeter temperature decreased slightly when the stirring was stopped. This was attributed to a combination of heat of stirring of the viscous solution, and conduction of heat to the calorimeter from the hands during the stirring. Correction to the observed temperature rise during the "reaction period" was made for these effects, and for heat transfer between calorimeter and jacket.

The energy unit used in the original calculation of the results is the international joule. Conversion to the conventional thermochemical calorie was made by the relation [13] 1 calorie $=4.1833$ int. $j$.

\section{Materials}

The samples of styrene and polystyrene used in the bomb-calorimetric measurements were obtained from the Dow Chemical Co. The styrene was a selected sample, and was purified at this Bureau ${ }^{3}$ by passing it through silica gel, by three fractional freezings, and by distillation in vacuum. Freezing curves indicated a purity of the final product of 99.95 mole percent. Mass spectrographic analysis ${ }^{4}$ indicated a composition of 99.91 mole percent styrene and 0.09 mole percent ethylbenzene. The observed bomb-calorimetric data on styrene were corrected for the presence of this amount of ethylbenzene by using the heat of combustion data reported by Prosen, Gilmont, and Rossini [14].

After purifiying the sample it was stored in an evacuated sealed glass container at the temperature of dry ice until time for making the calorimetric measurements. It was then warmed to room temperature, a sample was transferred to a glass bottle, and $10 \mathrm{ppm}$ of tertiary butyl catechol was added to this sample to inhibit polymerization. The calorimetric measurements on the monomer were completed within 1 month after it was warmed to room temperature.

The two samples of polystyrene obtained for the bomb-calorimetric measurements, samples I and II, were commercial unfractionated polymers, containing about 3 percent of methanol-soluble material (partly low-molecular-weight polymer and unpolymerized styrene). The monomer used was 99.7 percent styrene, and most of the impurity was ethylbenzene. Each sample was prepared by thermal polymerization without catalysts at a range of temperatures, the average for the two samples being of the order of $100^{\circ} \mathrm{C}$ and above, and may have had a wide range of molecular weights present. However, precipitation tests ${ }^{5}$ showed that as methanol was slowly added to a toluene solution of the polymer, a large fraction of the material was precipitated over a narrow range of added precipitant, indicating that a large portion of each polymer probably was of nearly uniform molecular weight.

\footnotetext{
3 The purification and testing for purity by observation of freezing behavior were done by members of the staff of the low-temperature laboratory at the Bureau.

${ }^{4}$ By A. K. Brewer.

${ }^{5}$ By I. C. Schoonover of the Bureau.
} 
The sample of polystyrene used in the measurements of heat of solution, sample III, was obtained from Monsanto Chemical Co. It was a commercial material designated as type $A$, and was prepared in the form of a fine powder by solution in toluene and precipitation with methanol in the manner described below for samples I and II.

The styrene used in heat of solution measure ments was a technical sample obtained from Dow Chemical of Canada, Ltd. Freezing curves indicated that it was 99.8 mole percent styrene, the most likely impurities being ethylbenzene and polystyrene.

A few preliminary bomb-calorimetric measurements were made on samples I and II of polystyrene without purification, except for removal of visible particles of foreign material. The remainder of each of these samples was purified at this Bureau, by the method of I. C. Schoonover, which produces a fine powder rather than a gel. According to this procedure, $20 \mathrm{~g}$ of the material was dissolved in $2 \frac{1}{2}$ liters of chemically pure filtered and distilled toluene by allowing the mixture to stand for $24 \mathrm{hr}$, with intermittent shaking. The solution was filtered through a fine sintered glass funnel. Two hundred milliliters of the filtered solution was slowly added to 3 liters of chemically pure methanol in a 4-liter Erlenmeyer flask, with continuous stirring. Stirring was continued for $1 / 2 \mathrm{hr}$ after all of the toluene solution had been added and the precipitate was then allowed to settle overnight.

The supernatant liquid was decanted, the precipitate collected upon a large sintered-glass funnel, and washed eight times with methanol.

When the entire amount of polystyrene solution had been treated in this manner, the precipitates were then dried for $18 \mathrm{hr}$ in a thin layer at $70^{\circ} \mathrm{C}$ under a pressure of about $75 \mathrm{~mm}$ of mercury. The dried material was ground, mixed, and dried for an additional $72 \mathrm{hr}$ under the same conditions with intermittent stirring to expose fresh surfaces. A test made by moistening the dried material with methanol and drying again indicated that the material probably did not retain methanol under these conditions of drying.

It is believed that the above treatment removed most of any monomer and low-molecular-weight polymer that may have been present. It was found, however, that the polymer increased in weight by about 0.1 percent during the drying process. One sample (not used for combustion measurements) that was kept for about 1 month under the above conditions of drying increased in weight by about 1 percent. Within the limits of precision of the measurements, the heats of combustion of the purified and unpurified samples per gram of carbon dioxide formed were the same. The heat of combustion of the purified material per gram of sample burned was found to be about 0.06 percent less than that of the unpurified material. These facts suggest that the removal of monomer and low molecular-weight polymer in the purification process did not affect the heat of combustion per gram of carbon dioxide formed by a measurable amount, and that the increase in weight of the material during drying was due to the absorption of gas, which behaved as an inert impurity.

The three samples of polystyrene were characterized, after purification, by viscosity determinations. Measurements were made with an Ostwald (Fenske type 50) viscometer at a temperature of $30.50^{\circ} \pm 0.05^{\circ} \mathrm{C}$. The viscometer was calibrated with water, and it was found that the kinetic-energy correction to the viscosity was negligible over the range of viscosities measured on the polystyrene samples. The viscosities of the polystyrene samples were meásured in toluene solutions at concentrations of $1,0.5,0.25$, and in some cases, $0.125 \mathrm{~g} / 100 \mathrm{ml}$ of solution. The results were plotted by the method of Huggins [15], and the following values obtained for the intrinsic viscosity $[\eta]$ and the constant $k^{\prime}$ in the Huggins ${ }^{6}$ equation:

\begin{tabular}{|c|c|c|}
\hline & {$[\eta]$} & $h^{\prime}$ \\
\hline Sample I_. & 1.650 & 0.206 \\
\hline Sample II ..... & 0.791 & .232 \\
\hline Sample III _.... & 1.255 & .217 \\
\hline
\end{tabular}

These data indicate that samples I and II, used in the bomb-calorimetric measurements, differed considerably in average molecular weight (sample I having about twice the molecular weight of sample II) and that the degree of polymerization

\footnotetext{
${ }^{6} \eta_{s p} / c=[\eta]+k^{\prime}[\eta] \eta_{s p}$, where $c$ is the concentration in grams per $100 \mathrm{ml}$ of solution, $\eta_{\bullet p}$ is specific viscosity, and $k^{\prime}$ is a constant that determines the dependence of the viscosity on concentration and depends on the type of polymer, on the solvent and on the temperature, but is supposed to depend only slightly, or not at all, on the molecular weight of the polymer.
} 
of sample III, used in the measurements of heat of solution was intermediate between those of samples I and II. It may be noted that there are not very wide differences among the values of $k^{\prime}$

\section{Results}

The results of the calibration experiments are given in table 1 . Because of slight changes in the calorimetric system resulting from repairs to the bomb, and the substitution of a new resistance thermometer for the one used initially, several series of calibration experiments were made during the course of the work. These are designated by the letters $A, B, C$, in table 1 .

TABLE 1.-Results of calibration of calorimeter with benzoic acid

\begin{tabular}{|c|c|c|}
\hline \multicolumn{2}{|c|}{ Observed energy equivalent at $28.5^{\circ} \mathrm{C}$ for series- } \\
\hline$A$ & $B$ & $C$ \\
\hline Int. $j /^{\circ} C$ & Int. $j /^{\circ} C$ & \\
13828.0 & 13825.9 & Int. $j /^{\circ} C$ \\
13823.6 & 13827.1 & 13826.9 \\
13828.6 & 13829.9 & 13821.9 \\
13826.0 & 13828.2 & 13822.6 \\
13827.3 & 13823.3 & 13827.4 \\
13823.9 & 13825.3 & 13835.0 \\
13825.2 & 13829.5 & 13832.5 \\
13818.8 & 13822.4 & 13829.0 \\
13825.7 & 13822.6 & 13822.9 \\
13827.0 & 13822.8 & 13823.8 \\
13824.8 & 13818.2 & 13825.5 \\
\hline $13825.4 \pm 0.8$ a & 13817.7 & $13826.7 \pm 1.2$ a \\
& 13823.2 & \\
\hline Mean & 13828.7 & \\
\hline & 13824.0 & \\
\hline & 13824.3 & \\
\hline
\end{tabular}

a See footnote 7, page 632 .

The results of measurements of heat of combustion are given in table 2 , where $-\Delta U_{B}$ is the observed heat of combustion in the bomb under the conditions specified in columns 2 and 3 of the table, and $-\Delta U_{c}^{\circ}$ represents the decrease in intrinsic energy accompanying the combustion reaction when the reactants (liquid styrene or solid polystyrene and gaseous oxygen) and products (gaseous carbon dioxide and liquid water) are all in their thermodynamic standard states. The letters $A, B, C$, following the material names in table 2 indicate the series of calibration experiments listed in table 1 , upon which the results are based.
TABLE 2.-Results of bomb-calorimetric measurements on polystyrene and styrene

\begin{tabular}{|c|c|c|c|c|}
\hline \multirow{2}{*}{$\begin{array}{l}\text { Mass of } \\
\text { sample }\end{array}$} & \multirow{2}{*}{$\begin{array}{c}\text { Initial } \mathrm{O}_{2} \\
\text { pressure, } \\
30^{\circ} \mathrm{C}\end{array}$} & \multirow{2}{*}{ Mass of $\mathrm{CO}_{2}$} & \multicolumn{2}{|c|}{ Heat of combustion at $30^{\circ} \mathrm{C}$} \\
\hline & & & $-\Delta U_{B}$ & $-\Delta U_{e}{ }^{\circ}$ \\
\hline \multicolumn{5}{|c|}{ POLYSTYRENE I $(A)^{a}$} \\
\hline $\begin{array}{c}g \\
1.04199 \\
0.83779 \\
.89085 \\
.87126 \\
.84294 \\
.70051\end{array}$ & $\begin{array}{l}\text { atm } \\
35.9 \\
35.8 \\
35.7 \\
35.7 \\
35.7 \\
35.8\end{array}$ & $\begin{array}{c}g \\
3.51789 \\
2.82821 \\
3.00708 \\
2.94205 \\
2.84516 \\
2.36437\end{array}$ & $\begin{array}{c}\text { Int. } j / g \mathrm{CO}_{2} \\
12273.0 \\
12276.5 \\
12275.3 \\
12273.2 \\
12273.6 \\
12276.5\end{array}$ & $\begin{array}{c}\text { Int. } j / g \mathrm{CO}_{2} \\
12265.5 \\
12269.4 \\
12268.1 \\
12266.0 \\
12266.5 \\
12269.6\end{array}$ \\
\hline \multicolumn{4}{|c|}{$\begin{array}{l}\text { Mean } \\
\text { Standard deviation of mean b }\end{array}$} & $\begin{array}{r}12267.5 \\
\pm 1.3\end{array}$ \\
\hline \multicolumn{5}{|c|}{ POLYSTYRENE II $(B)^{\text {a }}$} \\
\hline $\begin{array}{r}0.54714 \\
.99097 \\
.97718 \\
.98993 \\
.96938\end{array}$ & $\begin{array}{l}35.8 \\
35.8 \\
35.8 \\
35.8 \\
36.0\end{array}$ & $\begin{array}{l}\text { 1. } 84806 \\
\text { 3. } 34687 \\
\text { 3. } 29996 \\
\text { 3. } 34174 \\
\text { 3. } 27295\end{array}$ & $\begin{array}{l}12279.1 \\
12274.3 \\
12273.4 \\
12273.5 \\
12275.3\end{array}$ & $\begin{array}{l}12272.4 \\
12267.0 \\
12266.1 \\
12266.2 \\
12268.0\end{array}$ \\
\hline \multicolumn{4}{|c|}{$\begin{array}{l}\text { Seandard deviation of mean } \mathrm{b} \\
\text { Weighted mean for polystyrene } \\
\text { Standard deviation of weighted mean } \mathrm{b}\end{array}$} & $\begin{array}{r}12267.9 \\
\pm 1.6 \\
12267.6 \\
\pm 1.2\end{array}$ \\
\hline \multicolumn{5}{|c|}{ STYRENE $(C)^{\text {a }}$} \\
\hline $\begin{array}{r}1.17387 \\
0.77992 \\
.79241 \\
.73714 \\
.86098 \\
.72861 \\
.78500\end{array}$ & $\begin{array}{l}32.5 \\
32.6 \\
32.3 \\
32.8 \\
32.8 \\
32.7 \\
32.8\end{array}$ & $\begin{array}{l}3.96699 \\
2.63602 \\
2.67778 \\
2.49141 \\
2.91015 \\
2.46261 \\
2.65316\end{array}$ & $\begin{array}{l}12474.1 \\
12478.0 \\
12478.7 \\
12473.7 \\
12469.4 \\
12471.6 \\
12469.7\end{array}$ & $\begin{array}{r}\circ 12466.6 \\
12471.1 \\
12471.8 \\
12466.8 \\
12462.3 \\
12464.8 \\
12462.7\end{array}$ \\
\hline \multicolumn{4}{|c|}{$\begin{array}{l}\text { Mean } \\
\text { Standard deviation of mean } \mathrm{b}\end{array}$} & $\begin{array}{r}12466.6 \\
\pm 1.9\end{array}$ \\
\hline
\end{tabular}

a See preceding column for an explanation of the significance of the letters $A, B$, and $\mathrm{C}$.

b Each value of standard deviation of the mean was calculated from the data of the experiments with the styrene or polystyrene sample and the corresponding experiments with benzoic acid, in the manner described in footnote 7 , page 632 .

- The values of $-\Delta U_{\mathrm{c}}{ }^{\circ}$ for styrene were derived from the corresponding values of $-\Delta U_{B}$ by applying the Washburn correction and a correction of $34 \mathrm{ppm}$ for the ethylbenzene in the sample.

The values obtained for the mass of carbon dioxide formed in combustion, which is a measure of the amount of reaction, are lower than the corresponding values calculated stoichiometrically from the masses of samples burned, assuming that the composition of the samples is represented by $\left(\mathrm{C}_{8} \mathrm{H}_{8}\right)_{x}$. The average differences between observed and calculated masses of carbon dixoide 
are, for styrene, 0.029 percent, and for the samples of polystyrene I and II, respectively, 0.146 and 0.115 percent. Frequent measurements of the carbon dioxide formed in combustion of Standard Sample 39f of benzoic acid yielded results in agreement with calculated values within less than 0.01 percent on the average. The observed deficiency of carbon dioxide in the case of styrene can probably be attributed to air or moisture dissolved in the liquid. The deficiency in the case of the samples of polystyrene is probably due to the presence of nonhydrocarbon material in the samples as an impurity.

It will be seen from the data of table 2 that the values of $-\Delta U_{c}{ }^{\circ}$ for the two samples of polystyrene are practically identical, even though the indicated amounts of impurity were different. This suggests that a part of the nonhydrocarbon content of the samples behaved simply as an inert impurity, but as the combined uncertainties of the calorimetric results, and of the measurements of the carbon dioxide formed are of the same order of magnitude as the difference in indicated impurity in the two samples, no definite conclusion can be drawn as to this point. It is here assumed that the nonhydrocarbon content of the polystyrene samples is entirely inert impurity.

The data in table 2 then indicate that the heat of combustion of polystyrene per gram of carbon dioxide formed is independent of molecular weight, at least over the range of the material studied. The weighted mean of the values for the two samples is therefore taken as the value derived from the present measurements for the heat of ccmbustion of polystyrene.

In table 3 are given values of heat of combustion per mole (or per $\mathrm{C}_{8} \mathrm{H}_{8}$-unit) for styrene and polystyrene, calculated from the mean values given in table 2. In reducing the values at $30^{\circ}$ to $25^{\circ} \mathrm{C}$, use was made of unpublished data obtained at the Bureau on the heat capacities of polystyrene and styrene [16]. The values of heat capacities were 128.48 int. $\mathrm{j} / \mathrm{C}_{8} \mathrm{H}_{8}$-unit degree and 182.20 int. $\mathrm{j} /$ mole degree at $27.5^{\circ} \mathrm{C}$ for polystyrene and styrene, respectively.

The value derived from the data given in table 3 for the heat of polymerization of liquid styrene to solid polystyrene at $25^{\circ} \mathrm{C}$, that is, the difference between the values for heats of combustion of monomer and polymer is $-\Delta H_{\mathrm{P}}\left(25^{\circ} \mathrm{C}\right)=69.79 \pm$.
0.66 int.kj, ${ }^{7}$ or $16.68 \pm 0.16 \mathrm{kcal} / \mathrm{mole}$ of monomer. The data obtained in measurements of the integral heat of solution of polystyrene in styrene are given in table 4 . The values given represent the heat evolved when polystyrene is dissolved in styrene to form a solution containing an average of 6.9 percent by weight of polystyrene. This average concentration of polymer in the resulting solution was about the same as the concentration of polymer in the final solution obtained in the direct measurements of heat of polymerization [1] made at the Bureau.

TABLE 3.-Values of heat of combustion

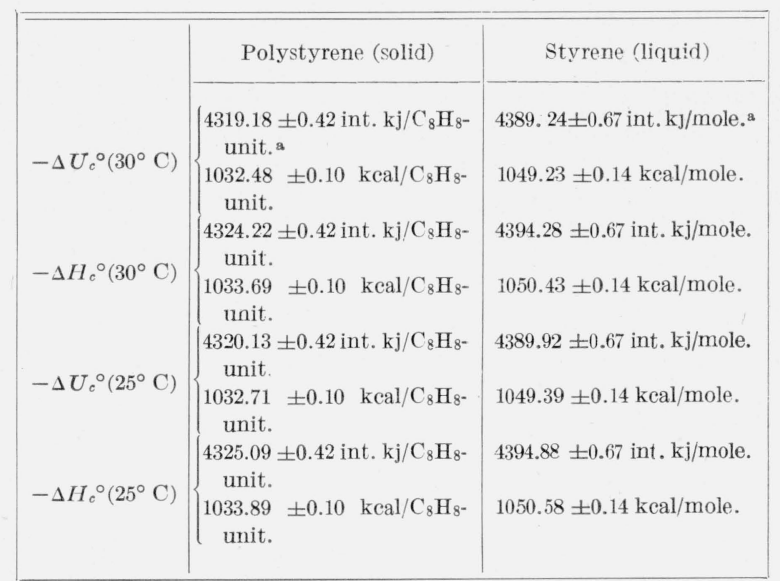

a See footnote 7

7 Except where otherwise noted, the number following each $\pm \operatorname{sign}$ is a measure of the precision of the result which is defined as follows: In the case of a value of heat of combustion, the measure of precision is taken as [17]

$$
s=Q \sqrt{\left(s_{E} / E\right)^{2}+\left(s_{Q} / Q\right)^{2}+\left(s_{B} / B\right)^{2}+\left(s_{R} / \bar{R}\right)^{2}}
$$

In this expression, $s_{E}$ is the standard deviation of the mean of the results of the series of experiments with benzoic acid to determine $E$, the energy equivalent of the calorimetric system; $s_{Q}$ is the standard deviation of the mean of the results of the series of experiments to determine $Q$, the heat of combustion of the sample; $\left(s_{B} / B\right)$ is an allowance of $5 \times 10^{-5}$ for the standard deviation of the value used for the heat of combustion of benzoic acid; and $\left(s_{R} / R\right)$ is an allowance of $5 \times 10^{-5}$ for the standard deviation associated with the determination of the amount of the combustion reaction from the mass of carbon dioxide formed. The corresponding measure of precision of the value of heat of polymerization is defined as

$$
s^{\prime}=\sqrt{\left(s_{m}^{\prime}\right)^{2}+\left(s_{p}^{\prime}\right)^{2}}
$$

In this expression $s_{m}{ }^{\prime}$ and $s_{p}{ }^{\prime}$ were calculated from the data of the heat of combustion measurements on monomer and polymer, respectively, by means of expressions of the form

$$
s_{m}^{\prime}=Q \sqrt{\left(s_{E} / E\right)^{2}+\left(s_{Q} / O\right)^{2}}
$$

Here it is assumed that systematic errors in the value used for the heat of combustion of benzoic acid and in the method of determining the amount of the combustion reaction will cancel in taking the difference between the heats of combustion of polymer and monomer.

"Standard deviation of the mean" as used above is defined as $(1 / \sqrt{n}) \times \sqrt{\Sigma d^{2} / n}$, where $d$ is the difference between a single observation and the mean, and $n$ is the number of observations. 
TABLE 4.-Results of measurements of the heat of solution of polystyrene in styrene

\begin{tabular}{|c|c|c|}
\hline \multirow{2}{*}{$\begin{array}{l}\text { Mass of poly- } \\
\text { styrene a }\end{array}$} & \multicolumn{2}{|c|}{$\begin{array}{l}\text { Observed heat of solution } \\
\qquad\left(-\Delta H, 25^{\circ} \mathrm{C}\right)\end{array}$} \\
\hline & $\begin{array}{l}\text { Int. } \mathrm{kj} / \mathrm{C}_{8} \mathrm{H}_{8-} \\
\text { u.iit }\end{array}$ & $\mathrm{kcal} / \mathrm{C}_{8} \mathrm{H}_{8}$-unit \\
\hline \begin{tabular}{l}
\multicolumn{1}{c}{$g$} \\
$0.897 \ldots \ldots$ \\
$0.998 \ldots \ldots$ \\
$0.986 \ldots$ \\
$1.106 \ldots \ldots$
\end{tabular} & $\begin{array}{l}3.99 \\
3.58 \\
2.91 \\
3.88\end{array}$ & $\begin{array}{r}0.95 \\
.86 \\
.69 \\
.93\end{array}$ \\
\hline $\begin{array}{l}\text { Mean } 0.997 \\
\begin{array}{l}\text { Standard de- } \\
\text { viation of } \\
\text { mean }\end{array}\end{array}$ & \pm 0.21 & \pm 0.05 \\
\hline
\end{tabular}

a Dissolved in $15.0 \mathrm{mi}$ of styrene.

These measurements of heat of solution are believed to be the only ones reported for a solution of polymer in its own monomer. The observed evolution of heat reported in this paper has been surprising to some persons with whom this work has been discussed.

It was expected that the heat of solution would be quite small considering the chemical similarity of the two materials. Flory [18] assumes that the heat of mixing of polystyrene and toluene is negligible, but Schulz [19] found an evolution of heat upon dissolving polystyrene in benzene. It may be noted that heat is evolved when cellulose derivatives are dissolved in various solvents [20, $21,22,23,24,25]$; heat is absorbed in rubbersolvent systems $[26,27,28]$ and the heat effect is zero with gutta-percha and toluene [29]. ${ }^{8}$ The fact that heat is evolved suggests that the attractive force between adjacent polymer molecules is less than that between polymer and monomer molecules.

Addition of the value $69.79 \pm 0.66$ int. $\mathrm{kj}$ or

${ }^{8}$ References numbered [19, 21, 22, 23, 24, 25 and 28] are to work in which the heat was measured calorimetrically. In references [20, 26, 27, and 29] the heat effect was calculated from osmotic-or vapor-pressure measurements.
$16.68 \pm 0.16 \mathrm{kcal} / \mathrm{mole}$ for heat of polymerization of liquid monomer to solid polymer to the value $3.59 \pm 0.21$ int. $\mathrm{kj} / \mathrm{C}_{8} \mathrm{H}_{8}$-unit, or $0.86 \pm 0.05 \mathrm{kcal} /$ $\mathrm{C}_{8} \mathrm{H}_{8}$-unit given in table 4 for the heat of solution of solid polystyrene in liquid styrene yields the value $73.38 \pm 0.69 \mathrm{int}$. $\mathrm{kj}$ or $17.54 \pm 0.16 \mathrm{kcal} / \mathrm{mole}$ of monomer for the heat of polymerization of liquid styrene at $25^{\circ} \mathrm{C}$ when the final product is a solution of polystyrene in liquid styrene. It would have been more satisfactory if the same sample of polystyrene could have been used in both the combustion and the solution measurements. However, it is thought that the branching, ring formation, or other differences that have been ascribed [30] to different conditions of polymerization probably would not have an effect greater than experimental error on the thermal values reported here. It will be noted that there is good agreement with the heat of polymerization as measured directly [1].

For convenient reference, a recapitulation of the essential numerical results obtained is as follows:

\begin{tabular}{|c|c|}
\hline & $-\Delta H^{\circ}{ }_{298.16}$ \\
\hline Heat of combustion: & \\
Monomer & $1050.58 \mathrm{kcal} / \mathrm{mole}$. \\
Polymer & $1033.89 \mathrm{kcal} / \mathrm{C}_{8} \mathrm{H}_{8}$-unit. \\
Heat of solution of polymer in monomer & $0.86 \mathrm{kcal} / \mathrm{C}_{8} \mathrm{H}_{8}$-unit. \\
Heat of polymerization to: & $16.68 \mathrm{kcal} / \mathrm{mole}$. \\
$\quad \begin{array}{l}\text { Solid polymer } \\
\text { Solution }\end{array}$ & $17.54 \mathrm{kcal} / \mathrm{mole}$. \\
\end{tabular}

\section{Discussion}

The method that has been used for calculating heat of polymerization from bomb-calorimetric data is based on the assumption that the polymerization reaction is represented by

$$
x \mathrm{C}_{8} \mathrm{H}_{8}(\mathrm{liq}) \rightarrow\left(\mathrm{C}_{8} \mathrm{H}_{8}\right)_{x}(\text { solid })
$$

This equation may be more appropriately written in the form

$$
x \mathrm{CH}_{2}=\mathrm{CHC}_{6} \mathrm{H}_{5} \rightarrow \mathrm{CH}_{3}-\mathrm{CHC}_{6} \mathrm{H}_{5}-\left(\mathrm{CH}_{2}-\mathrm{CHC}_{6} \mathrm{H}_{5}\right)_{x-2}-\mathrm{CH}=\mathrm{CHC}_{6} \mathrm{H}_{5}
$$

The double bond could conceivably be located in other parts of the chain, or as suggested by Risi and Gauvin [31] it could be destroyed by cycliza- tion of the terminal linkages with the production of a molecule having an indane ring at the end:

$$
\mathrm{CH}_{3}-\mathrm{CHC}_{6} \mathrm{H}_{5}-\left(\mathrm{CH}_{2}-\mathrm{CHC}_{6} \mathrm{H}_{5}\right)_{x-3}-\mathrm{CH}_{2}-\mathrm{CH} / \mathrm{C}_{6} \mathrm{H}_{4}
$$


According to information supplied by the Dow Chemical Co., polystyrene samples I and II were prepared by straight thermal polymerization of styrene, which was at least 99.7 percent pure. The impurity was mostly ethylbenzene, with approximately $100 \mathrm{ppm}$ of some organic peroxide. It therefore seems unlikely that the composition of the polymer molecules differed from that indicated by the formula $\left(\mathrm{C}_{8} \mathrm{H}_{8}\right)_{x}$ by amounts sufficient to affect the heat of combustion of the polymer by a significant amount. In particular, the presence of fragments of catalyst or solvent molecules on the ends of the polymer chains $[32,33,34,35,36,37]$ seems extremely unlikely.

As noted previously, the amount of carbon dioxide formed in the combustion of the polystyrene samples was less than that calculated from the mass of sample burned. The fact that the amount of nonhydrocarbon impurity indicated by the deficiency of carbon dioxide is about the same as the increase in weight of the polymer samples during drying makes it appear likely that the nonhydrocarbon impurity was largely gas absorbed during drying. If this gas was oxygen that reacted chemically to become a part of the polymer molecules, the heat of combustion of the polymers per gram of carbon dioxide formed would be lower than that of a polymer having the composition $\left(\mathrm{C}_{8} \mathrm{H}_{8}\right)_{x}$, and the value derived from the heat of combustion data for the heat of polymerization according to reaction 1 would be correspondingly too high. Making reasonable assumptions as to the molecular weights of the polymers, it is estimated that 0.15 percent by weight of oxygen chemically combined with sample I of polystyrene would lower its heat of combustion per gram of carbon dioxide by an amount corresponding to an increase of about 3 percent of the heat of polymerization. The corresponding effect of 0.11 percent combined oxygen in the case of polystyrene sample II would be of the order of 2 percent of the heat of polymerization. As noted previously, however, the experimental data on heats of combustion indicate that the gas absorbed by the polymer in drying did not combine chemically with it, but behaved simply as an inert impurity.

\section{Previous Work}

Measurements of the heats of combustion of styrene and two samples of polystyrene have been reported by Luschinsky [38]. One of his samples of polystyrene (sample $A$ ) was prepared by polymerizing styrene for $6 \mathrm{hr}$. at $180^{\circ} \mathrm{C}$, dissolving the product in toluene and distilling off the toluene and any remaining monomer in vacuum, and then redissolving the product in toluene and drying in high vacuum at $100^{\circ} \mathrm{C}$. His other sample (sample $B$ ) was obtained by fractionating a part of sample $A$ by precipitation from solution in methyl ethyl ketone in such a manner that a sample having a narrow range of molecular weights was obtained.

Measurements of heat of combustion were made by means of a bomb calorimeter. The method used to prevent evaporation of styrene was probably not completely effective. The amount of reaction in each case was determined from the mass of sample burned.

The values reported for heat of combustion of styrene, polystyrene $A$, and polystyrene $B$ are $1045.4,1034.8$, and $1031.6 \mathrm{kcal} / \mathrm{mole}$ of monomer, respectively. Certain small corrections would have to be applied to these values to convert them to the same basis as the values of heat of combustion reported in this paper, but as these corrections would be substantially the same for styrene, and for the two samples of polystyrene, the resulting values for heat of polymerization will not be affected by omission of these corrections. The values of heat of polymerization of styrene to solid polystyrene derived from Luschinsky's data are 10.6 and $13.8 \mathrm{kcal} / \mathrm{mole}$ of monomer for polystyrene samples $A$ and $B$, respectively.

Prosen, Gilmont, and Rossini [14] have reported the velue $1050.40 \pm 0.20 \mathrm{kcal} / \mathrm{mole}$ for the heat of combustion, $-\Delta H_{c}^{\circ}$, of liquid styrene at $25^{\circ} \mathrm{C}$. This value is in agreement within 0.017 percent with that derived from the results presented in this paper. Further references to earlier work will be found in reference [14].

Schulz [19] has made measurements of the integral heat of solution of polystyrene in benzene and has reported an evolution of 415 to 445 cal $/ \mathrm{C}_{8} \mathrm{H}_{8}$-unit, the concentration of the solution being 3.3 percent by weight. This evolution of heat is only about half of that obtained in the work reported in this paper in which styrene was the solvent, and the concentration was 6.9 percent.

Votinov, Kobeko, and Marei [39] derived the 
value $23 \mathrm{kcal} / \mathrm{mole}$ for the heat of depolymerization of polystyrene from the difference in activation energies of polymerization and depolymerization. They also reported, without experimental details, the values 9,831 and $10,041 \mathrm{cal} / \mathrm{g}$ (1023.8 and $1045.7 \mathrm{kcal} /$ mole of monomer) for the heats of combustion of polymer and monomer, respectively, and $21.9 \mathrm{kcal} / \mathrm{mole}$ for the heat of polymerization of styrene derived from the values of heat of combustion.

Stanley [40] reported the value $20 \mathrm{kcal} / \mathrm{mole}$ of monomer for the heat of polymerization in styrene solution. The source of this figure was not given.

Direct measurements of the heat evolved during polymerization of styrene were made by Goldfinger, Josefowitz, and Mark [2]. They reported the value $15.0 \mathrm{kcal} /$ mole of monomer for the heat of polymerization, at $70^{\circ}$ to $140^{\circ} \mathrm{C}$, the final product being a solution in which the monomer was 35 to 85 percent polymerized.

Direct measurements [1] of the heat of polymerization of styrene made at the low temperature laboratory of the Bureau have produced the result $17.8 \mathrm{kcal} / \mathrm{mole}$ of monomer, which is in good agreement with the corresponding value 17.54 $\mathrm{kcal} /$ mole of monomer reported in this paper.

\section{References}

[1] I. C. Schoonover, W. J. Ferguson, and F. G. Brickwedde. Publication pending.

[2] G. Goldfinger, D. Josefowitz, and H. Mark, J. Am. Chem. Soc. 65, 1432 (1943).

[3] R. S. Jessup, J. Research NBS 29, 247 (1942) RP1499.

[4] E. W. Washburn, BS J. Research 10, 525 (1933) RP546.

[5] T. W. Richards and F. Barry, J. Am. Chem. Soc. 37, 933 (1915).

[6] R. S. Jessup, J. Research NBS 18, 115 (1937) RP966.

[7] H. C. Dickinson, Bul. BS 11, 189 (1914) S230.

[8] E. F. Mueller, Bul. BS 13, 547 (1916) S288.

[9] R. S. Jessup, and C. B. Green, J. Research NBS 13, 469 (1934) RP721.

[10] E. J. R. Prosen and F. D. Rossini, J. Research NBS 27, 289 (1941) RP1420.

[11] F. D. Rossini, BS J. Research 6, 37 (1931) RP260.

[12] M. Shepherd, Anal. Chem. 19, 77 (1947).
[13] E. F. Mueller and F. D. Rossini, Am. J. Phy (1944) ; see also, Premier Rapport de la Commission Permanente de Thermochimie, International Union of Chemistry, p. 3 (1934).

[14] E. J. Prosen, R. Gilmont, and F. D. Rossini, J. Research NBS 34, 59 and 65 (1945) RP1628 and RP1629.

[15] M. L. Huggins, Ind. Eng. Chem. 35, 980 (1943).

[16] R. D. Rands, J. L. Prather, R. B. Scott, W. J. Ferguson, and F. G. Brickwedde (unpublished).

[17] F. D. Rossini and W. E. Deming, J. Wash. Acad. Sci. 29, 416 (1939).

[18] P. J. Flory, J. Chem. Phys. 10, 51 (1942).

[19] G. V. Schulz, Z. physik. Chem. [A] 179, 321 (1937).

[20] O. Hagger and A. J. A. van der Wyk, Helv. Chim. Acta 23, 484 (1940).

[21] W. L. H. Moll and G. W. Fuller, Kolloid-Z. 80, 320 (1937)

[22] G. V. Schulz, Z. physik. Chem. [B] 52, 253 (1942).

[23] T. Nakashima and N. Saito, J. Soc. Chem. Ind. Japan 38, Suppl. binding 232 (1935).

[24] S. M. Lipatov and Z. A. Preobrazhenskaya, Kolloid-Z. 68, 324 (1934).

[25] V. A. Kargin and S. P. Papkov, J. Phys. Chem. (U. S. S. R.) 7, 483 (1936).

[26] G. Gee and L. R. G. Treloar, Trans. Faraday Soc. 38, 147 (1942).

[27] K. H. Meyer, E. Wolff, and C. G. Boissonas, Helv. Chim. Acta 23, 430 (1940).

[28] L. Hock and H. Schmidt, Kautschuk 10, 33 (1934).

[29] E. Wolff, Helv. Chim. Acta 23, 439 (1940).

[30] T. Alfrey, A. Bartovies, and H. Mark, J. Am. Chem. Soc. 65, 2319 (1943).

[31] J. Risi and D. Gauvin, Can. J. Research 14, B, 255 (1936).

[32] F. R. Mayo, J. Am. Chem. Soc. 65, 2324 (1943).

[33] C. C. Price, R. W. Kell, and E. Krebs, J. Am. Chem. Soc. 64, 1103 (1942).

[34] C. C. Price and B. E. Tate, J. Am. Chem Soc. 65, 517 (1943).

[35] P. D. Bartlett and S. G. Cohen, J. Am. Chem Soc. 65, 543 (1943).

[36] H. F. Pfann, D. J. Salley, and H. Mark, J. Am. Chem. Soc. 66, 983 (1944).

[37] W. Kern and H. Kämmerer, J. prakt. Chem. 161, 81 (1942).

[38] W. v. Luschinsky, Z. physik, Chem. [A] 18\%, 384 (1938).

[39] A. Votinov, P. Kobeko, and F. Mareı̌, J. Phys. Chem. (U. S. S. R.) 16, 106 (1942).

[40] H. M. Stanley, Chemistry \& Industry 16, 93 (1938).

Washington, January 21, 1947. 